\title{
Emergency preparedness for long lasting releases - accident scenarios
}

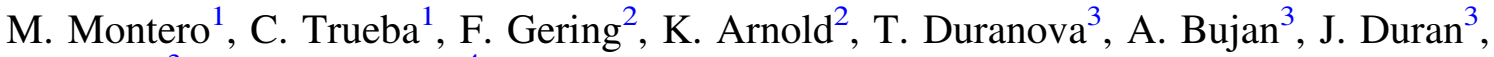 \\ L. Bohun ${ }^{3}$ and T. Peltonen ${ }^{4}$ \\ ${ }^{1}$ CIEMAT, Environment Department, Av. Complutense 40, 28040 Madrid, Spain. \\ 2 BfS - Federal Office for Radiation Protection, Ingolstaedter Landstr. 1, 85764 Oberschleissheim, Germany. \\ 3 VUJE, Inc., Okružná 5, 91864 Trnava, Slovakia. \\ ${ }^{4}$ Radiation and Nuclear Safety Authority (STUK), Finland, Säteilyturvakeskus, Finland.
}

\begin{abstract}
The Fukushima-Daiichi accident has demonstrated the possibility of long-lasting releases of radionuclides from a nuclear power plant (NPP) over several weeks, which has led to the need to review if current procedures of external emergency planning are suitable for these situations. Under the framework of the "PREPARE" project one work package focused on "Review of the emergency preparedness in case of long-term emissions". The aim is to test the current off-site nuclear emergency planning along Europe and to derive recommendations on how to improve it. In this context, a statistical study has been proposed by using potential long lasting release scenarios in combination with different weather conditions over a significant period of time (for instance one year) in some selected locations. This paper presents the results obtained in the development of accidental scenarios for a range of meteorological conditions representative for NPP sites in several European countries, i.e. Germany, Slovakia, Finland and Spain.
\end{abstract}

Keywords: reactor severe accident scenario / long lasting release / weather scenarios

\section{Introduction}

In all countries with nuclear installations detailed emergency management strategies have been developed in the past. In nearly all cases such strategies are based on accident scenarios where the duration of the release of radionuclides to the environment is limited to some hours or at maximum a few days. The Fukushima-Daiichi accident has demonstrated the possibility of long-lasting releases of radionuclides from a nuclear power plant (NPP) over several weeks, which has led to the need to review the suitability of the current procedures of external emergency planning for these situations.

Under the framework of the "PREPARE" project a work package focused on "Review of the emergency preparedness in case of long-term emissions" has been developed. Two objectives have been followed: first, to evaluate, using realistic scenarios, the consequences of these accidents according the type of reactor involved and the varying conditions that influence the pattern of dispersion and deposition of radioactive contamination; and second, to explore whether these effects can be reduced and properly managed with the strategies and procedures currently planned. The aim has been to test the current off-site nuclear emergency planning along Europe and to derive recommendations how to improve it. In this context, a statistical study has been proposed by using potential long lasting release scenarios in combination with different weather conditions over a significant period of time (for instance one year) in some selected locations. This paper presents the results obtained in the development of accidental scenarios for a range of meteorological conditions representative for NPP sites in several European countries, i.e. Germany, Slovakia, Finland and Spain.

\section{Accident scenarios}

The accident scenarios developed in this study should be representative for potential accident situations that may arise in the territory chosen. For this, the following elements have been taking into account:

- The location of NPP, which determines the zone potentially affected and the characteristics (topography, land cover, agricultural production, population, etc.) that may influence both the pattern of contamination and the radiological consequences. A range of sites has been selected in Germany, Slovakia, Finland and Spain. In Figure 1, the location of the selected NPPs is shown.

- The source term (ST), which determines timing and magnitude of radioactive release to environment according the type of reactor. The description of STs selected is presented in the previous paper (Bujan et al., 2016).

- The weather conditions, which determine the variability of atmospheric dispersion and deposition of radioactive substances. In one approach, typical weather scenarios could be derived from historical data from continuous 


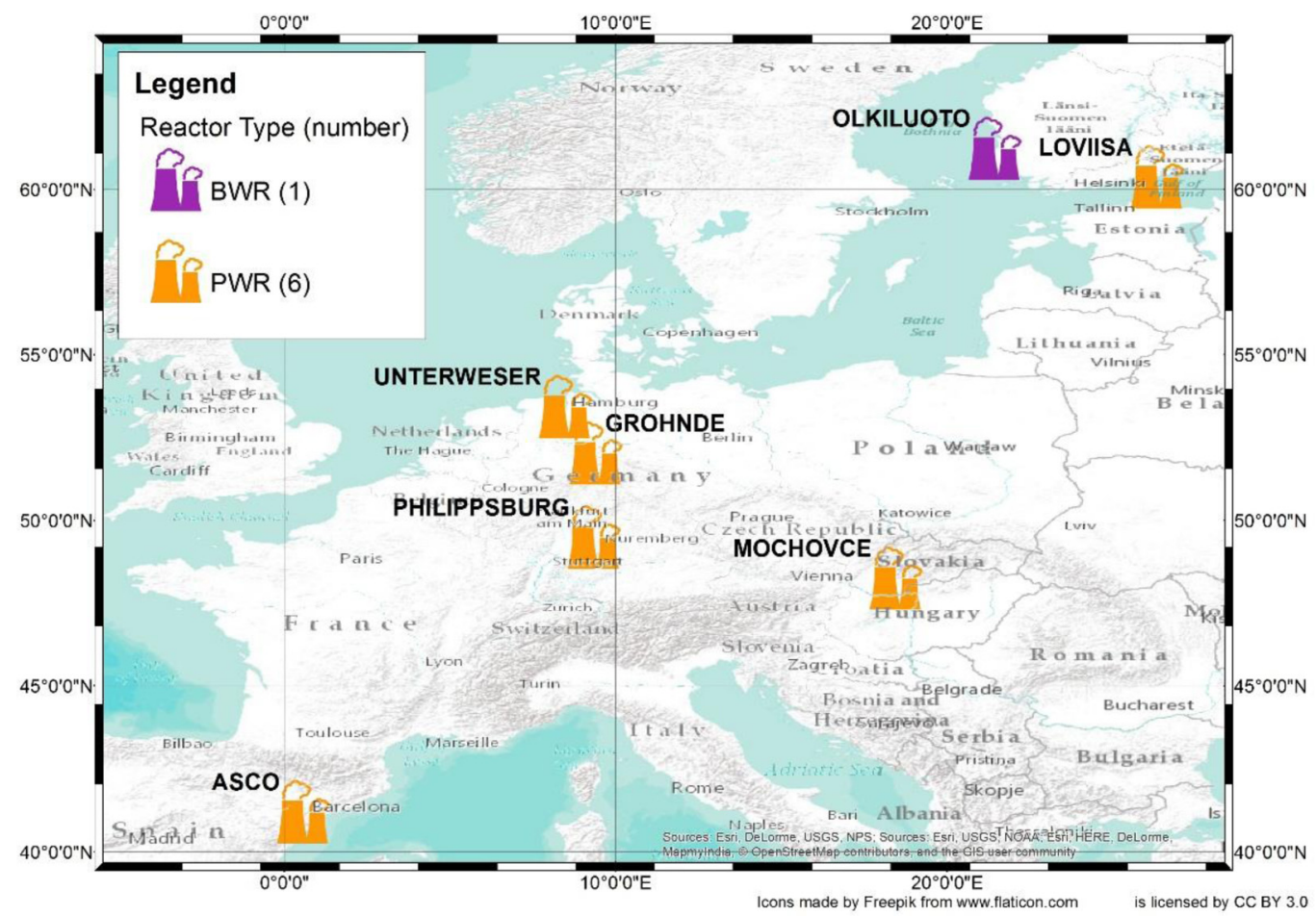

Figure 1. Selected NPP sites for accident scenarios.

monitoring of meteorological parameters at nuclear power plants. Another approach was based on historical numerical weather predictions (NWP) for various locations of nuclear power plants in Europe.

In order to realise the statistical study proposed in the work package, a set of accident scenarios has been derived by the combination of ST's with the meteorological situations selected along a time period (Meteo Data set) for each type of reactor considered in each site $((N$ (periods $) \times N$ (Dataset) $\times N(\mathrm{NWP}) \times N(\mathrm{ST} / \mathrm{NPP})))$.

In the following a summary of the scenarios selected in each country is presented. All data regarding the described accident scenarios are taken from the report (Gering et al., 2014).

\subsection{Accident scenarios for German NPP's}

The German task group has selected the NPP sites and weather scenarios based on the impact of the meteorological differences between NPP sites in Germany on results of dispersion modelling and resulting radiological consequences. Three sites have been selected:

- NPP Unterweser: site in the north of Germany, very close to the coast, flat terrain;

- NPP Grohnde: site in the middle of Germany, moderately structured terrain;

- NPP Philippsburg: site in the south of Germany in the Rhine Valley, surrounded by structured terrain.

A study with measurement data available from these NPP sites has revealed that meteorological conditions - as stability class, wind speed and wind direction and the monthly mean values for precipitation - show rather strong deviations between the sites, but not much for each site from year to year. This ensures, on the one hand, a broad representation of all German NPPs and, secondly, that the specific conditions at each site can be properly represented with a data set for an annual period.

Therefore, a NWP data set with 365 daily meteorological situations, along one year, has been provided for each selected NPP by the German weather service to prepare the accident scenarios used in the statistical study. The main characteristics of these scenarios are presented in Table 1.

\subsection{Accident scenarios for Slovakian NPP's}

The Mochovce NPP site has been chosen for the analyses as Slovakian NPP. Input data concerning the conditions of dispersion in the atmosphere include meteorological data and geographical data describing the NPP surroundings. The Mochovce area is located at the junction of two geological subsystems of the Alpine - Himalayan systems, the Carpathians and Pannonian Basin at an elevation of 261 metres above sea level. The Mochovce NPP sites in the mild climate zone influenced by both oceanic and continental climate. An altering of oceanic and continental impacts and southern exchange of air masses over a wide range from tropical to arctic origin creates the main climate patterns of this region.

Necessary meteorological data have been provided by the Slovak Hydrometeorological Institute (SHMÚ). Statistically processed meteorological data from hourly measurements SHMÚ for the years 1981-2010 have been analysed to derive the typical dispersion conditions in the Mochovce NPP locality. Meteorological variables, as temperature, atmospheric precipitation, stability class, wind speed and wind direction, show a pattern with typical annual and daily temperatures cycle, influencing by Mediterranean and Eurasian continent 
Table 1. Summary of accident scenarios developed in Germany and Slovakia.

\begin{tabular}{|c|c|c|c|c|c|c|c|}
\hline Location & $\begin{array}{l}\text { Country } \\
\text { Site }\end{array}$ & \multicolumn{3}{|c|}{ GER } & \multicolumn{3}{|c|}{$\frac{\text { SK }}{\text { NPP Mochovce }}$} \\
\hline \multirow[b]{2}{*}{ Source term } & Type of reactor & \multicolumn{3}{|c|}{ PWR } & \multicolumn{3}{|c|}{ VVER } \\
\hline & Source term name & FKI & FKF & FKA & STC6-8d & STC10-8d & STC30-8d \\
\hline \multirow{5}{*}{$\begin{array}{l}\text { Weather } \\
\text { scenarios }\end{array}$} & Time period covered & \multicolumn{3}{|c|}{$01.11 .2011-31.10 .2012(1 \mathrm{y})$} & \multicolumn{3}{|c|}{ 01.01.2010-31.12.2010 (1 y) } \\
\hline & Type of data & \multicolumn{3}{|c|}{ Numerical weather prediction } & \multicolumn{3}{|c|}{ Monitoring data } \\
\hline & Time resolution & \multicolumn{3}{|c|}{$\begin{array}{l}1 \mathrm{~h} \text { resolution, } 72 \mathrm{~h} \text { prognosis per data set, } \\
\text { updated prognosis every } 12 \mathrm{~h}\end{array}$} & \multicolumn{3}{|c|}{ Hourly } \\
\hline & Spatial resolution & \multicolumn{3}{|c|}{$100 \mathrm{~km} \times 100 \mathrm{~km}$, grid resolution $7 \mathrm{~km}$} & \multicolumn{3}{|c|}{ Single point measurements } \\
\hline & No of scenarios ${ }^{a}$ & 1095 & 1095 & 1095 & & 432 & \\
\hline
\end{tabular}

${ }^{\mathrm{a}}(N($ periods $) \times N($ Startimes $) \times N(\mathrm{NWP}) \times N(\mathrm{ST} / \mathrm{NPP}))$.

and affected by the global warming, precipitations with double annual rainfall course, a predominance of stability class D and prevailing winds in directions NW (29\%), E (19\%), and SE $(18 \%)$ with moderated speed.

From these analyses, the year 2010 has been selected as time period for the computational studies accomplished in the work package. A cyclic sampling has been used to extract the measured wind speed, wind direction, atmospheric stability category and rain intensity, every 61 st hour record of the meteorological data measurements from SHMU. The set of 144 meteorological conditions obtained of the real meteorological hourly data at Mochovce NPP location in the year 2010 has been used with meteorological conditions for the assumed accident with an accident conditions stored in the source term file STC10-8d. The main characteristics of these scenarios are presented in Table 1.

\subsection{Accident scenarios for Finnish NPP's}

There are two NPP sites in Finland and both have been chosen for this study.

- NPP Loviisa: Located in the city of Loviisa, on the south coast (Gulf of Finland). There are two VVER-440 PWR reactors operating.

- NPP Olkiluoto: Located in municipality of Eurajoki on the west (Gulf of Bothnia) coast, near the city of Rauma. There are two BWR reactors operating and one EPR reactor under construction.

Statistical analyses of meteorological measurements from the weather mast in each site have provided the wind roses represent the typical wind conditions of both sites. In case of Loviisa, mast data covers $\sim 9$ years period and for Olkiluoto, mast covers $\sim 5$ years period. In both cases the data interval for wind rose calculations is $3 \mathrm{~h}$.
It should be noted that weather conditions around Finnish NPP's differ from other plants in this study because they are located at a coastal area. The wind conditions over the Gulf of Finland (Loviisa) and the Gulf of Bothnia (Olkiluoto) are characterised by the sea-breeze. The main factor contributing to the sea-breeze is the temperature difference between land and sea areas. The sea-breeze typically occurs from April to August and it can have a significant effect on dispersion conditions by recirculating air over the shoreline and thus raising levels of radioactive substances higher than expected.

In order to obtain the accident scenarios, Finnish Meteorological Institute (FMI) produces NWP data for STUK's purposes. In this study weather data from NWP models HIRLAM RCR and ECMWF has been used. STUK doesn't use NWP data directly but instead requests particle trajectories calculated by FMI's long-range dispersion model SILAM. These particle trajectories can be later used in STUK's dose calculation model VALMA as an input. Four different one week periods, with interval of 3 months to get seasonal variation, have been chosen to represent general weather conditions. In each period a data set of five days with variable start times are selected to combine with the ST's defined previously (Bujan et al., 2016) in each site. In total 80 accident scenarios have been used to realise the statistical study. Table 2 shows the summary of these scenarios.

\subsection{Accident scenarios for Spanish NPP's}

The area around the Ascó NPP has been selected as the territory for the simulation of a severe accident at a nuclear power plant. It is included in the Nuclear Emergency Plan of the province of Tarragona - Catalonia Generalitat (PENTA). ${ }^{5}$

5 PENTA. Off-site Nuclear Emergency Plan for the Ascó and Vandellós NPPs, Tarragona (Spain). 
Table 2. Summary of accident scenarios developed in Finland and Spain.

\begin{tabular}{|c|c|c|c|c|}
\hline \multirow{2}{*}{ Location } & \multirow{2}{*}{$\begin{array}{l}\text { Country } \\
\text { Site }\end{array}$} & \multicolumn{2}{|c|}{ FIN } & \multirow{2}{*}{$\frac{\text { E }}{\text { NPP Ascó }}$} \\
\hline & & NPP Loviisa & NPP Olkiluoto & \\
\hline \multirow[b]{2}{*}{ Source term } & Type of reactor & PWR & BWR & PWR \\
\hline & Source term name & $\begin{array}{l}\text { LO-NCR- } \\
\text { APC04 }\end{array}$ & OL-RHR-12 & MA-SBO-173 \\
\hline \multirow{10}{*}{$\begin{array}{l}\text { Weather } \\
\text { scenarios }\end{array}$} & \multicolumn{3}{|c|}{$13.05 .2013-20.05 .2013$} & \multirow{4}{*}{$\begin{array}{c}01.07 .2012- \\
31.07 .2012\end{array}$} \\
\hline & \multirow{3}{*}{ Time period covered } & \multirow{2}{*}{\multicolumn{2}{|c|}{$\begin{array}{l}13.08 .2013-20.08 .2013 \\
13.11 .2013-20.11 .2013\end{array}$}} & \\
\hline & & & & \\
\hline & & \multicolumn{2}{|c|}{ 13.02.2014-20.02.2014 } & \\
\hline & $\begin{array}{l}\text { Data sets of Meteo/ } \\
\text { period }\end{array}$ & \multicolumn{2}{|c|}{5} & 24 \\
\hline & Type of data & \multicolumn{2}{|c|}{$\begin{array}{l}\text { Particle trajectories calculated by } \\
\text { Finnish Meteorological Institute } \\
\text { (FMI) }\end{array}$} & Numerical Weather Prediction (re-analysis data) \\
\hline & Time resolution & \multicolumn{2}{|c|}{$\begin{array}{l}72 \mathrm{~h} \text { prognosis for particle } \\
\text { trajectories, based on daily four } \\
48 \mathrm{~h} \text { regional forecasts and four } \\
48 \mathrm{~h} \text { mesoscale forecasts for } \\
\text { Northern Europe }\end{array}$} & $\begin{array}{l}1 \mathrm{~h} \text { resolution, update period } 6 \text { hours, data } \\
\text { interval } 3 \mathrm{~h} \text {, prognosis duration to } 180 \mathrm{~h}\end{array}$ \\
\hline & Spatial resolution & \multicolumn{2}{|c|}{$\begin{array}{l}\text { Horizontal resolution of the } \\
\text { HIRLAM RCR model is } 7.5 \mathrm{~km} \text {. }\end{array}$} & Calculation area in JRODOS: $80 \mathrm{~km} \times 80 \mathrm{~km}$ \\
\hline & Provider & \multicolumn{2}{|c|}{$\begin{array}{l}\text { Particle trajectories calculated by } \\
\text { Finnish Meteorological Institute } \\
\text { (FMI) }\end{array}$} & NOMADS GRIB1 resolution: 1 degree pixel \\
\hline & No of scenarios & 40 & 40 & 46 \\
\hline
\end{tabular}

The area has a Mediterranean climate, with mild winters and somewhat hot summers. The prevailing winds are warm and humid.

As the other task groups, historical data from continuous monitoring of meteorological parameters provided by the Spanish National Weather Service (AEMET) and the own meteorological station of the Ascó NPP has been used to obtain representative weather scenarios (for typical or extreme situations). The monthly mean values for precipitation and the differences and deviations in the distribution for stability class, wind speed and wind direction depending of the season have been analysed. The annual wind rose shows a strong directional influence of topography, prevailing winds clearly aligned with the direction of the valley, SSE (19\%) and NNW $(15 \%)$. As there are marked seasonal differences, with extremes cases in summer and winter, a period of one month in each of these seasons has been selected regarded as for statistical analysis of radiological consequences. The NPW data have been provided by NOAA's NOMADS server to cover the months January and July of 2012. A total of 44 datasets has been used for purposes of statistical study. In addition, two cases study in specific conditions regarding rainfall and wind speed/direction to obtain a maximum spreading of contamination in the area were selected in January and July, respectively. The main characteristics of these scenarios are presented in Table 2.

\section{Conclusions}

This paper presents the results obtained in the development of accidental weather scenarios for a range of meteorological conditions representative for NPP sites in several European countries.

The main characteristics of these weather scenarios are the following:

- Weather scenarios are provided for seven NPP's in four European countries, i.e. Germany, Slovakia,FinlandandSpain.

- The data includes both numerical weather predictions and on-site monitoring data.

- The scenarios based on measurements differ substantially regarding time periods covered and time resolutions: e.g. one data set consists of 10 minutes monitoring data over several years, one other data set e.g, includes hourly monitoring data over one year and one other data set e.g. provides monthly mean values of monitoring data over 15 years.

- The scenarios based on numerical weather predictions mainly differ regarding the time periods covered, which range from a few representative weather scenarios for summer and winter for the NPP Ascó (46), about 80 different scenarios for the Finnish NPPs and 365 scenarios (for every day of a year) for the German NPPs. 
The combination of the weather scenarios with the ST' results in a significant number of accident scenarios that can represent the variety of conditions for severe accidents with long-lasting releases in Europe. This data has subsequently been used to assess the potential radiological consequences and evaluate the current nuclear emergency planning for long lasting releases (see Peltonen et al., 2016; Gering et al., 2016).

Acknowledgement. The research leading to these results has received funding from the European Atomic Energy Community Seventh Framework Programme FP7/2012-?2013 under grant agreement 323287.

\section{References}

Bujan A. et al. (2016) Emergency preparedness for long lasting releases - source terms, Radioprotection 51 (HS2), S67-S71.

Gering F. et al. (2014) Review of emergency preparedness for long lasting releases - accident scenarios, Project Deliverable D1.2, PREPARE(WP1)-(14)-02.

Gering F. et al. (2016) Emergency preparedness for long lasting releases - overview and conclusions, Radioprotection $\mathbf{5 1}$ (HS2), S63-S65.

Peltonen T. et al. (2016) Emergency preparedness for long lasting releases - assessment of radiological consequences, Radioprotection 51 (HS2), S79-S81.

Cite this article as: M. Montero, C. Trueba, F. Gering, K. Arnold, T. Duranova, A. Bujan, J. Duran, L. Bohun, T. Peltonen. Emergency preparedness for long lasting releases - accident scenarios. Radioprotection 51(HS2), S73-S77 (2016). 